\title{
A phenological model for the soybean
}

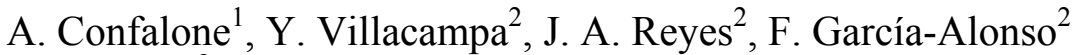 \\ \& F. Verdú ${ }^{2}$ \\ ${ }^{1}$ Cátedra de Agrometeorología, \\ Facultad de Agronomía de Azul-UNCPBA, Buenos Aires, Argentina \\ ${ }^{2}$ Departamento de Matemática Aplicada, Universidad de Alicante, \\ Alicante, Spain
}

\begin{abstract}
Predicting the time of soybean flowering is a critical step for crop management practices and for the development of crop models. The main objective of this study was to quantify the effect of the photoperiod and of temperature on the duration of the different phenological periods (flowering, first pod and physiological maturity), and to evaluate the response of a simple linear model for predicting phenological periods in Azul, centre of Buenos Aires, Argentina. It also used the methodology defined in the work of Summerfield et al. (Measurement and prediction of flowering in soybeans in fluctuating field environments. In: World Soybean Research Conference 4, 1989, Buenos Aires. Argentina Soybeans Association, 1989. pp. 82-87) which generates families of mathematical models with non-linear parameters and includes the study of linear models to obtain other models. Finally the sensitivity of the models to the variations produced by the experimental data was studied by applying the methodology used in Summerfield et al., Verdu and Villacampa (A computer program for a Monte Carlo analysis of sensitivity in equations of environmental modelling obtained from experimental data. Advances in Engineering Software. Vol. 33, N $\mathrm{N}^{\mathrm{o}}$ 6. pp.351-359, 2002) and Verdu and Villacampa (A Computational algorithm for the multiple generation of nonlineal mathematical models and stability study. Advances in Engineering Software. In Press). This allowed the model to be selected according to the criteria.
\end{abstract}

Keywords: soybean, photoperiod, temperature, development, modelling, stability. 


\section{Introduction}

Temperature and photoperiod produce qualitative changes throughout the soybean cultivation cycle and are therefore important for its development (Hadley et al., [8]; Summerfield et al., [17]; Grimm et al., [7]).

Several studies have characterised the sowing-flowering phenological subperiod of soybean cultivation with regard to its sensitivity to temperature and photoperiod (Major et al., [12]; Jones and Laing, [10]; Hodges and French, [9]; Wilkerson et al., [22]; Rodrigues et al., [14]).

Sensitivity to the photoperiod varies according to the genotype. The degree of response to the photoperiodic stimulation is the main determining factor of the area of adaptation of different crops. With sensitive soybean crops, the response to the photoperiod is quantitative and not absolute, meaning that flowering will occur anyway. However, the time required will depend on the length of the day, with the induction being faster with short days than with long days. In this way, floral induction provokes the transformation of the vegetative meristems (differentiation of stalks and leaves) into reproductive (flower primordia), determining the final size of the plants (number of nodes) and thus their potential yield. Late-maturing crops are generally more sensitive to the photoperiod than early crops (Lawn and Byth, [11]; Major et al., [12]).

Garner and Allard [6] concluded that in environments with a constant photoperiod, temperature has a significant influence on determining the time of flowering. There is an inverse relationship between the average temperature of a site and the number of days needed to reach the flowering stage (Pascale, [13]).

The effect of the photoperiod and temperature on the flowering period of soybean has been studied using a quantitative relationship between these variables. Major et al. [12] used a multiplicative model of temperature and photoperiod to describe the time of flowering of soybean. Sinclair et al. [15] used linear and logistic models based on temperature and photoperiod to predict the date of flowering of soybean crops.

Predicting the date when the phenological events of soybean occur is important for crop management and for use in growth and production models (Wang et al. [21]). Knowledge of the dates of the occurrence of phenological events allows us to manage the crop better. We also avoid the periods of stress that characterise certain environments where soybean is cultivated and we can identify the relationship with the production of dry material and grain.

Use of the concept of development rate (inverse to duration) developed by Wit et al. [23] was a major advance in the prediction of the phenological behaviour of soybean crops. Hadley et al. [8] used this concept to define the development rate as the inverse of the time between sowing and flowering $(1 / f)$. In this way, if a crop has a long period between sowing and flowering (f: days), it will have a low development rate $\left(1 / f\right.$ days $\left.^{-1}\right)$. We can then analyse the length of the period by means of the $1 / f$ as a linear additive function of the average temperature $(T)$ and photoperiod $(F)$ for the period in question, using the equation: 


$$
\frac{1}{f}=a^{\prime}+b^{\prime} T+c^{\prime} F \text {, }
$$

where $1 / f$ is the development rate, the values of $T$ and $F$ represent the average temperature and photoperiod between sowing and flowering, and $a^{\prime}, b^{\prime}, c^{\prime}$ are empirical coefficients; $b^{\prime}$ and $c^{\prime}$ are estimators of the sensitivity to temperature and photoperiod respectively. With genotypes that are not sensitive to the photoperiod or below a threshold photoperiod, equation 1 only includes the first two terms. This simple approach has been successfully used with soybean development prediction models for a wide range of genotypes and environments (Summerfield et al., [17]).

This article aims to quantify the effect of photoperiod and temperature on the duration of the flowering period, as well as in other phenological sub-periods of the crop. To this end, families of models will be identified that allow us to predict the different phenological periods of soybean crops in Azul, in the centre of the province of Buenos Aires, Argentina.

\section{Materials and methods}

An experiment was conducted from 1997 to 2002 on a Typic Argiudol in the experimental farm of the Facultad de Agronomía - UNCPBA, located in Azul, Buenos Aires, Argentina $\left(36^{\circ} 45^{\prime} \mathrm{S} ; 5^{\circ} 50^{\prime} \mathrm{W} ; 132 \mathrm{~m}\right.$ elevation). Two indeterminate cultivars (Asgrow 4656 and Don Mario 4800 RR) were sown to achieve a final density of 30 plants $/ \mathrm{m}^{2}$.

The temperature and photoperiod data were obtained from the Centro Regional de Agrometeorología (Regional Agrometeorology Centre) FAAUNCPBA (CRAGM-Boletines 1997-2003).

The treatments used in this work were with irrigation (soil kept at approximately field capacity) and without limitations of nutrients.

The water applied daily to supplement rainfall was distributed by a drip system and was calculated using the methodology recommended by the FAO (Allen et al., [1]). The field capacity value was determined using the Cassel and Nielsen method (Cassel and Nielsen, [2]). Weekly soil water content measurements were made with gravimetric samples (Gardner, [5]).

Monitoring of the temporal evolution of the phenology of the different bean crop sowing dates had to be carried out visually, three times a week, using the development stages key proposed by Fehr et al. [4].

Every two days, visual observations were carried out to check the foliar expansion of four marked plants. This was carried out for each plot and for each sowing date. A leaf was regarded as expanded when its base was flat, losing the characteristic rolled appearance of the young leaf.

The plants in each plot were regarded as having reached a certain stage or phase of development when $50 \%$ of the plants showed the morphological characteristics described in the key. 
In order to create the models, the following phenological phases equivalent to the key proposed by Fehr et al. [4] after sowing were analysed:

- $\quad$ Flowering (F): $50 \%$ of the plants with one flower open on any node on the main stalk (R1; Fehr et al., [4]).

- $\quad$ Start of pods (1V): $50 \%$ of the plants with $0.5 \mathrm{~cm}$ pods on any node on the main stalk (R3; Fehr et al., [4]).

- $\quad$ Physiological maturity (MF): 50\% of the plants with mature pods (R7; Fehr et al., [4]).

\section{Models}

In order to obtain the models defined on the basis of the experimental data, the methodologies defined by Spss. [16] and Verdu and Villacampa [19] were used. The former was used to seek linear models and the latter to obtain families of non-linear models in the parameters, also being able to obtain the linear models defined on the basis of Spss. [16].

The phenological stages defined by sowing-flowering, flowering-first pod and first pod-maturity were defined. For each of these stages, models were generated to study the days passed since sowing, $f$. Models were determined to show us their variation on the basis of the sum of the thermal time or "degree days" and the photoperiod.

\subsection{Models for the Asgrow 4656 cultivar}

Mathematical models were developed for this cultivar that quantify the days since sowing. Of the family of models obtained, the linear model could be used for all phenological stages.

The sowing-flowering stage obtained the model:

$$
f=0.1026 * \text { Suma Temp }-0.0726 * F+1.7, \quad \mathrm{R}^{2}=0.9
$$

The flowering-first pod stage obtained the model:

$$
f=0.105 * \text { Suma Temp }+8.639 * F-137.924, \quad \mathrm{R}^{2}=0.9
$$

The first pod-maturity stage obtained the model:

$$
f=0.044 * \text { Suma Temp }-12.975 * F+231.823, \quad \mathrm{R}^{2}=0.9
$$

\subsection{Models for the D. Mario cultivar}

Mathematical models were developed for this cultivar that quantify the days since sowing. Of the family of models obtained, the linear model could be used for all phenological stages.

In the sowing-flowering stage:

$$
\begin{gathered}
f=0.079 * \text { Suma Temp }+5.77 * F-85.98, \quad \mathrm{R}^{2}=0.9 \\
f=0.079 * \text { Suma Temp }-1.637+\left(0.931^{*} F-12.675\right)^{3}, \mathrm{R}^{2}=0.9
\end{gathered}
$$


In the flowering-first pod stage:

$$
f=0.082 * \text { Suma Tempe }+8.79 * F-134.6347, \quad \mathrm{R}^{2}=0.9
$$

In the first pod-maturity stage:

$$
f=0.00557 * \text { Sum Temp }-9.9817 * F+166.384, \mathrm{R}^{2}=0.9
$$

\subsection{Stability of the models}

The stability of the models was studied by applying the methodology developed in (Verdu and Villacampa, [18]; Villacampa et al. [20]).

The linear models of the Asgrow 4656 cultivar were stable when carrying out perturbations of up to $20 \%$ in the three phenological stages. The stability of the models (Eq. 2), (Eq. 3) and (Eq. 4) can be seen in Fig1, Fig 2 and Fig 3, respectively:

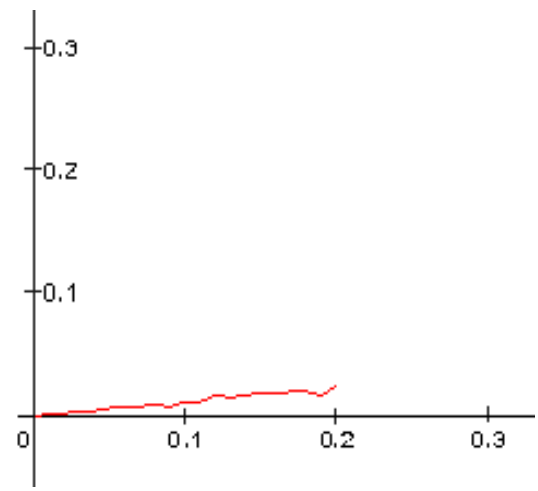

Figure 1.

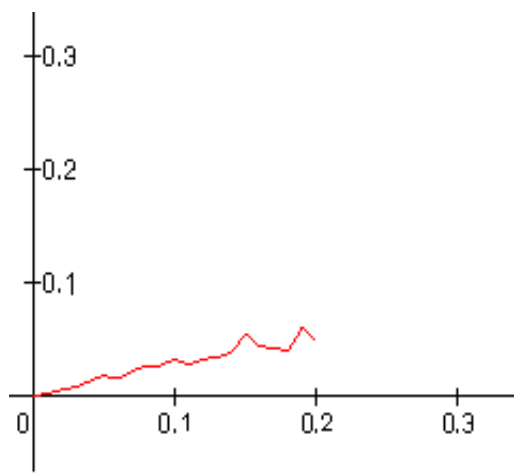

Figure 2.

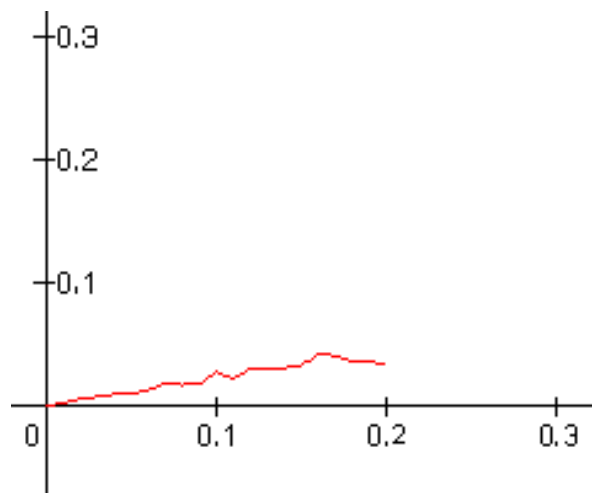

Figure 3. 
The $x$-axis represents the percentage of the perturbation carried out on the experimental data and the $y$-axis represents the variation of a model as a percentage.

The stability of the D. Mario cultivar was also studied. In this case, the linear models (Eq. 7) and (Eq. 8) are stable. However, the linear model (Eq. 5) corresponding to the sowing-flowering stage was not stable and only tolerated perturbations of up to $1 \%$ of the experimental data. This led to the new stable model defined in (Eq. 6) being obtained.

The stability of the models (Eq. 7) and (Eq. 8) can be seen in Fig. 4 and Fig. 5 respectively.

In Fig. 6 it can be seen that the linear model defined by (Eq. 5) is not stable. Fig. 7 shows the stability graph for the model defined in (Eq. 6).

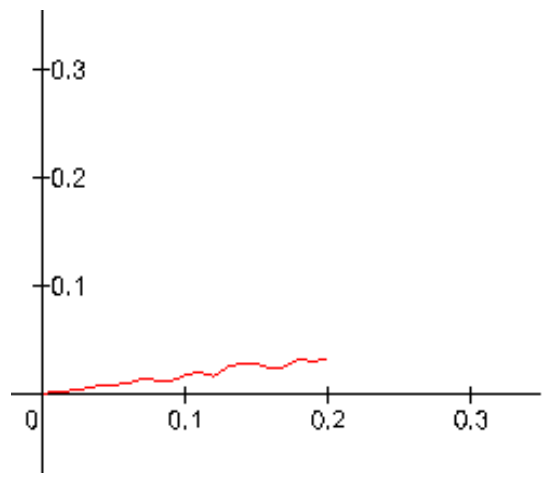

Figure 4 .

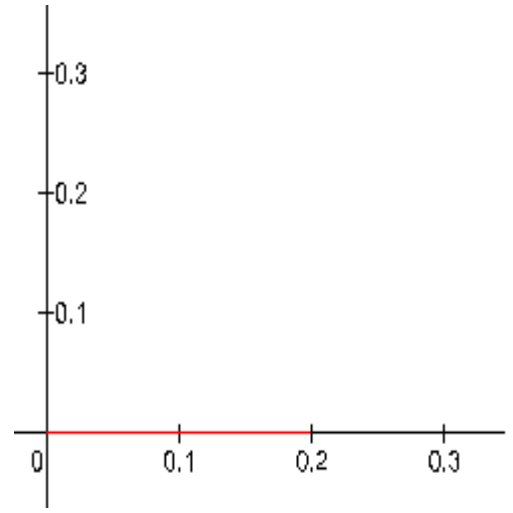

Figure 5.

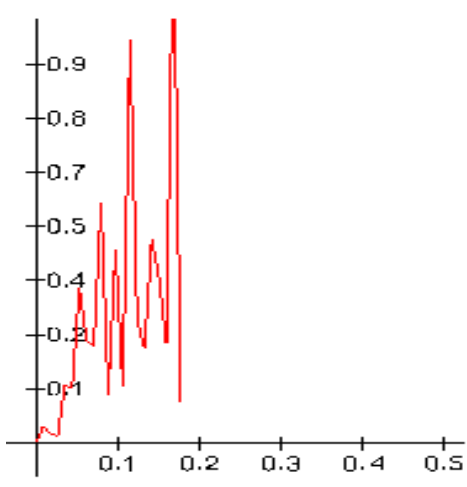

Figure 6.

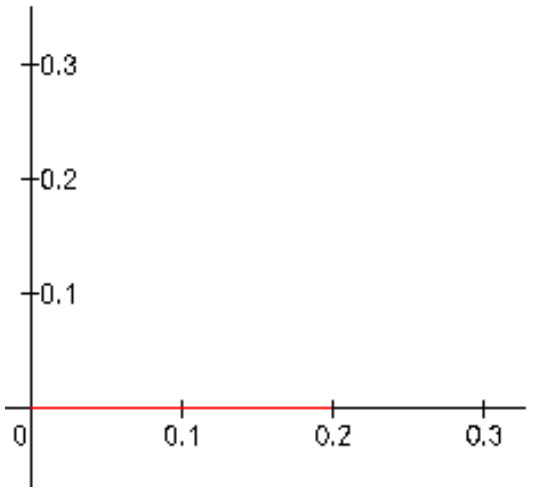

Figure 7. 


\section{Conclusions}

The models obtained show that the phenology of soybean is highly dependent on temperature and photoperiod.

Each cultivar shows a different degree of sensitivity to each of the abovementioned factors, giving different models depending on the cultivar and the phenological stage in question. The linear models are seen to be stable except for the sowing-flowering phenological stage of the D. Mario cultivar. However, a stable non-linear model was obtained. The stability was analysed using perturbations of up to $20 \%$ carried out on the experimental data.

The same methodology was used to generate models for the development rate $1 / f$ as proposed by Hadley et al. In this case, the models were not stable, meaning that the models obtained for $\mathrm{f}$ were regarded as more appropriate.

These models allow us to predict the phenology of soybean in the centre of the province of Buenos Aires.

\section{Acknowledgement}

This work was supported in part by funds from AE/07/074 (YVE) from Generalitat Valenciana.

\section{References}

[1] Allen, R. G., Pereira, L. S., Raes, Smith , D , M., Crop evapotranspiration. Guidelines for computing crop water requirements, FAO Irrigation and drainage paper $\mathrm{n}^{\circ} 56$. FAO, 1998.

[2] Cassel, D.K.; Nielsen, D.R. Field capacity and available water capacity, In, Klute, A. (ed). Methods of soil analysis, Madison, ASA-SSSA, Monograph nº, pp. 25, 1986.

[3] Cragm - Boletín Agrometeorológico del Centro-Sur de la Provincia de Buenos Aires.,Facultad. Agron. Azul, Buenos Aires, 1997,1998, 2002 y 2003.

[4] Fehr, W. R., Calviness, C. E., Burmood, D. T.; Pennington, J. S., Stage of development description for soybean, Glycine max (L.) Merrill, Crop Science, Madison, v. 11, pp. 929-931, 1971.

[5] Gardner, W.H., Water content In, Klute, A. (ed.). Methods of soil analysis. ASA, CSSA, and SSSA, Madison, WI, pp. 493-594, 1986.

[6] Garner, W. W., Allard, H. A., Photoperiodic response of soybeans in relation to temperature and other environmental factors, Journal of Agricultural Research, Washington, v. 41, pp. 719-735, 1930.

[7] Grimm, S.S., Jones, J.W., Boote, K.J., Hesketh, J.D. Parameter estimation for predicting flowering date of soybean cultivars. Crop Science, v. 33, pp. 137-144, 1993.

[8] Hadley, P., Roberts, E. H., Summerfield, R. J.; Mincchin, F. R. Effects of temperature and photoperiod on flowering in soya bean [Glycine max (L.) 
Merril]: a quantitative model. Annals of Botany, London, v.53, pp. 669$681,1984$.

[9] Hodges, T., French, V., Soyphen: soybean growth stages modeled from temperature, daylength, and water availability, Agronomy Journal, Madison, v. 77, pp. 500-505, 1985.

[10] Jones, P. G., Laing, D. R., Simulation of the phenology of soybeans, Agricultural Systems, Oxford, v. 3, pp. 295-311, 1978.

[11] Lawn, R. J., Byth, D. E., Response of soya beans to planting date in South-Eastern Queensland. I. Influence of photoperiod and temperature on phasic development patterns. Australian Journal of Agricultural Research, Collingwood, v. 24, pp. 67-80, 1973.

[12] Major, D. J., Johnson, D. R., Tanner, J. W., Anderson, I. C., Effects of daylength and temperature on soybean development, Crop Science, Madison, v. 15, pp. 174-179, 1975.

[13] Pascale, A. J. Tipos agroclimáticos para el cultivo de la soya en la Argentina, Revista de la Facultad de Agronomía e Veterinaria, Buenos Aires, v. 17, pp. 31-38, 1969.

[14] Rodrigues, O.; Didonet, A., Lhamby,J.; Bertagnolli, P.; Luz, J. Resposta quantitativa do florescimento da soja à temperatura e ao fotoperíodo. Pesquisa Agropecuaria Brasileira, v.36, pp. 431-437, 2001.

[15] Sinclair, T. R., Kitani, S., Hinson, K., Bruniard, J., Horie, T. Soybean flowering date: linear and logistic models based on temperature and photoperiod. Crop Science, Madison, v. 31, pp. 786-790, 1991.

[16] Spss. Inc. Software. (1999). Chicago. EE.UU.

[17] Summerfield, R.J., Roberts, E. H., Lawn, R.J. Measurement and prediction of flowering in soybeans in fluctuating field environments. In: World Soybean Research Conference 4, 1989, Buenos Aires. Argentina Soybeans Association, 1989. pp. 82-87.

[18] Verdu, F \& Villacampa, Y. A computer program for a Monte Carlo analysis of sensitivity in equations of environmental modelling obtained from experimental data. Advances in Engineering Software. Vol. 33, $\mathrm{N}^{\mathrm{o}}$ 6. pp.351-359, 2002.

[19] Verdu, F \& Villacampa, Y. A Computational algorithm for the multiple generation of nonlineal mathematical models and stability study. Advances in Engineering Software. In Press.

[20] Villacampa, Y; Verdu, F, Pérez, A. A Stability theory for model systems. Kybernetes. Vol.36, No.5-10.pp. 1-23, 2007.

[21] Wang, Z.; Reddy, R. V.; Quebedaux, B. Growth and photosynthetic responses of soybean to short-term cold temperature. Environmental and Experimental Botany, W. Conshohocken, v. 37, pp. 13-24, 1997.

[22] Wilkerson, G. G.; Jones, J. W.; Boote, K. J.; Buol, G. S. Photoperiodically sensitive interval in time to flower of soybean. Crop Science, Madison, v. 29, pp. 721-726, 1989.

[23] Wit, C. T.; Brouwer, R.; Vries, F. W. T. P. The simulation of photosynthetic systems. In: SETLIK, I. (Ed.). Prediction and measurement of photosynthetic productivity. Wageningen: PUDOC, 1970. pp. 47-70. 